\title{
Child Neurology: Siblings with infantile epilepsy and developmental delay
}

\section{A circuitous path to genomic diagnosis}

Yin Liu, MD, PhD, David Michelson, MD, Robin Clark, MD, and June-Anne Gold, MD

Neurology ${ }^{\circledR}$ 2018;91:143-147. doi:10.1212/WNL.0000000000005815

\section{Abstract}

\section{Objective}

Chromosome 14q11-q22 deletion syndrome (OMIM 613457) is a rare genomic disorder with a variable phenotype.

\section{Methods}

We report 2 full siblings, a brother and sister, with a unique familial $2.4 \mathrm{Mb}$ microdeletion at 14q13.1-14q13.3 by microarray (first identified in the brother, Mayo Clinical Laboratories, 2010).

\section{Results}

Both children presented with infantile spasms that evolved to intractable epilepsy and profound developmental delay. They share distinctive dysmorphic features: long expressionless facies, full cheeks, flattened midface, full lips, and generalized hypotonia. Only the sister has hemophagocytic lymphohistiocytosis (HLH). Testing in the brother revealed 3 variants of unknown significance (VUS) (Greenwood Genetics, epilepsy/seizure panel, 145 genes, 2015). The sister had normal results with a different gene panel (GeneDx, infantile epilepsy panel, 75 genes, 2016) but it did not include the 3 genes in which VUS were identified in her brother. Whole exome sequencing in the mother, father, and both siblings was negative without VUS (GeneDx, XomeDx, 2016). There were no variants within the deleted interval in the intact allele for both children. Parental fluorescent in situ hybridization studies for 14q13.1-14q13.3, done in 2017, were normal. Haplotype analysis of the intact chromosome 14 in the sister supported paternal origin for the deletion and likely germline mosaicism in the father. Haploinsufficiency of genes in the deleted region has not been associated with an abnormal phenotype.

\section{Conclusions}

These children have a specific, recognizable neurodevelopmental phenotype and 14q13 microdeletion. This report highlights the challenges of coordinating and interpreting genetic testing in syndromic epilepsy.

\author{
Correspondence \\ Dr. Liu \\ yiliu@llu.edu
}




\section{Glossary}

FISH = fluorescent in situ hybridization; HLH = hemophagocytic lymphohistiocytosis; NSVD = normal spontaneous vaginal delivery; SNP = single nucleotide polymorphism; VUS = variants of uncertain significance; WES = whole exome sequencing.

Two siblings were born to a healthy, nonconsanguineous Hispanic couple. The mother was 19 years old during the first pregnancy and 26 years old during the second pregnancy and both pregnancies were uncomplicated.

The brother, currently 7 years old, was born at $9 \mathrm{lb} 1 \mathrm{oz}$ via normal spontaneous vaginal delivery (NSVD). He was admitted at 2 weeks of age for suspected seizures. Routine EEG was normal. A brain MRI showed bilateral choroid plexus cysts. At 8 months of age, he was diagnosed with infantile spasms and then West syndrome. He did not improve despite treatment with $\mathrm{ACTH}$, phenobarbital, levetiracetam, and topiramate. MRI at 9 months showed interval development of mild diffuse cerebral atrophy. At 1 year and 7 months of age, a gastrostomy tube was placed due to dysphagia and failure to thrive. He was diagnosed with aspiration pneumonia and taken completely off of oral feedings at 2 years. Echocardiogram was normal at 4 years of age. His seizures remain intractable despite numerous medication trials, ketogenic diet, and implantation of a vagus nerve stimulator. He is severely delayed, nonverbal and nonambulatory, and unable even to sit unassisted. He lacks spontaneous and purposeful hand use and is cortically blind with partial hearing impairment.

His sister was born at full term via NSVD. She was admitted to the neonatal intensive care unit at day 9 for suspected seizures. Video EEG showed numerous electroclinical events arising from midline and central regions. Basic metabolic screening and infection workup were negative. Brain MRI showed bilateral choroid plexus cysts and small cavum septum pellucidum. MRS was normal. She was later diagnosed with West syndrome with persistent hypsarrhythmia and ongoing seizures despite treatment with levetiracetam, phenobarbital, topiramate, valproic acid, and clobazam.

Hemophagocytic lymphohistiocytosis (HLH) was diagnosed at 5 weeks of age. She was treated according to the HLH 2004 protocol with cyclosporine, etoposide phosphate, dexamethasone, and intrathecal methotrexate. She is currently in remission. Bone marrow transplant was considered but deferred due to parental concerns about her poor neurodevelopmental prognosis. She had dilated cardiomyopathy secondary to chemotherapy at 11 weeks of age, which later resolved. She was also diagnosed with cortical visual impairment. At 17 months of age, she remains severely delayed with no head control and no ability to roll over or sit independently. She coos more than her brother did but has no words.

On examination, the children shared some clinical findings, including generalized hypotonia and dysmorphic facial features (figure). They have long but flat, expressionless facies with posteriorly rotated ears, short columella, full lips with a tented upper lip, and loose and soft skin with tapered fingers. The brother has brachycephaly, low anterior and posterior hairlines, and thick coarse dark hair with unusual hair whorls. He has large eyes, with grey sclerae and arched and flared eyebrows. His ears are thin with underfolded helical rims bilaterally. His nose is long and tubular. He has deep palmar creases, hypermobile joints, and several café-au-lait spots on his right shoulder that are

\section{Figure Features of the siblings}

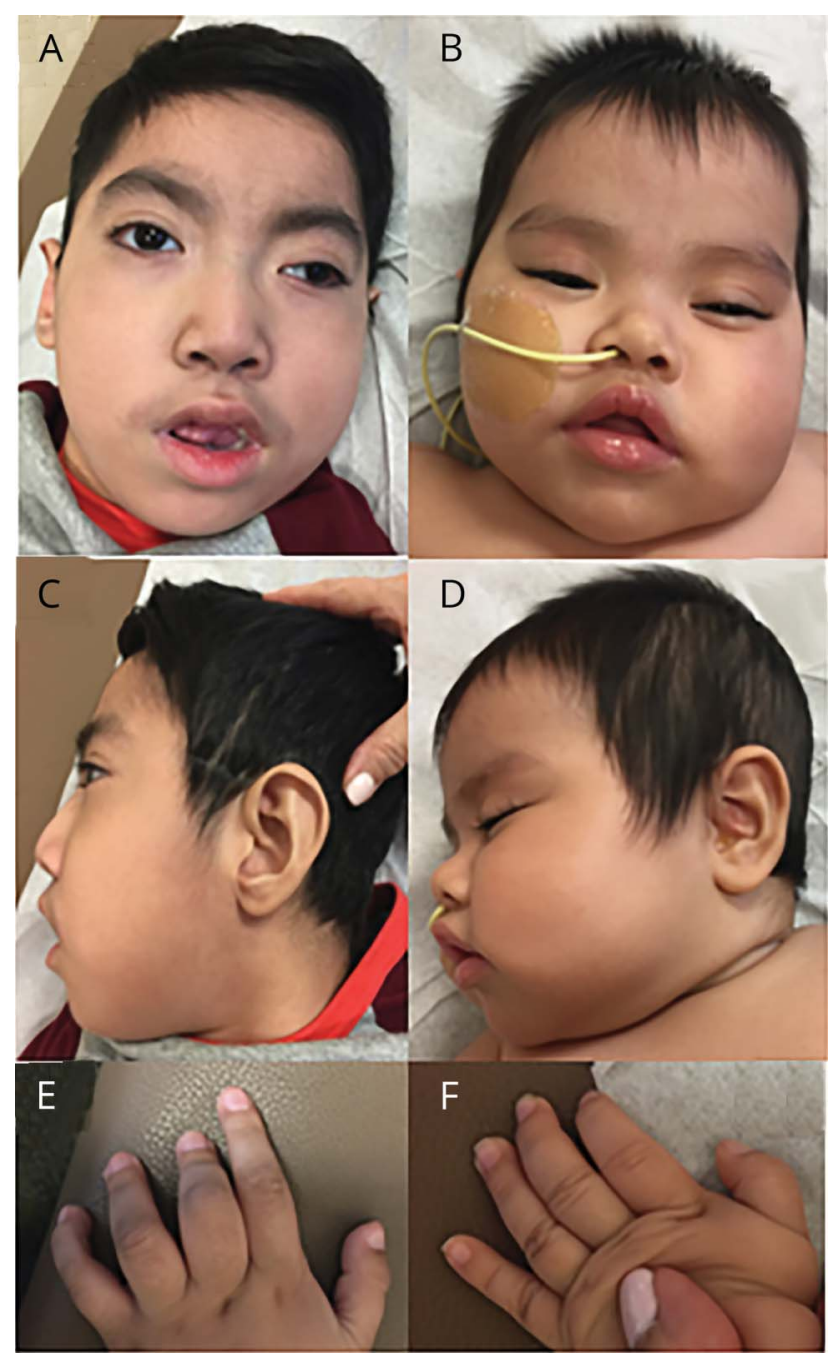

The brother $(A, C)$ has a long expressionless face, disconjugate gaze, brachycephaly, low anterior and posterior hairlines, unusual hair whorls, arched and flared eyebrows, grey sclera, large and posteriorly rotated ears, and a long, tubular nose with a short columella. His mouth is open at rest. The sister $(B, D)$ has a long, expressionless face, large and posteriorly rotated ears, bitemporal narrowing, hypertelorism, and a tented upper lip. Both siblings $(E, F)$ have tapered fingers. 
approximately $2 \times 3 \mathrm{~cm}$. He has bilateral equinovarus contractures with broad first toes and wide sandal gaps. The sister has a rounder face but has bitemporal narrowing, a wide nasal bridge, and hypertelorism. Her nipples are wide-spaced.

An array comparative genomic hybridization on the brother in 2010 showed a 2.4-MB interstitial deletion from 14q13.1 to $14 q 13.3(33,301,123-35,730,707)$ [hg18]. An updated report in 2017 revealed 22 known genes within the deleted interval as shown in the table. However, no information regarding a phenotype associated with heterozygous deletion of any of these genes was available. Parental fluorescent in situ hybridization (FISH) testing was offered at that time. An epilepsy gene panel (Greenwood Genetics, epilepsy/seizure panel, 145 genes) done in 2015 showed heterozygosity for missense variants of uncertain significance (VUS) in SZT2, PTCH1, and ASPM. Targeted testing of the parents showed the SZT2 and ASPM variants to be maternal in origin and the $P T C H 1$ variant to be paternal in origin. Both parents are asymptomatic.

A single nucleotide polymorphism (SNP) chromosomal microarray done on the sister soon after birth in 2016 revealed a 2.4MB deletion from 14q13.1 to $14 q 13.3$ (34,211,404-36,648,257) [hg19] that involved 21 known genes (table). There was no clear phenotype associated with haploinsufficiency of any of these genes. An infantile epilepsy gene panel done on the sister (GeneDx, Infantile Epilepsy Panel, 75 genes, 2016) was negative for mutations, deletions, or duplications, although this panel did not include SZT2, PTCH1, or ASPM.

Whole exome sequencing (WES) was done in April 2016 with the sister as the proband and the mother, father, and brother for comparison. This test did not identify any pathogenic variants in genes related to or possibly related to the patient's phenotype. The ASPM, PTCH1, and SZT2 genes were closely reviewed, with $100 \%$ coding region coverage. Close review of the haploinsufficient $14 \mathrm{q} 13$ region demonstrated no reportable variants in the proband. Therefore, they were not evaluated in the comparators per standard laboratory reporting protocol. Parental FISH studies done in 2017 were normal, showing no signs of the 14q13.1-14q13.3 deletion found in the 2 children.

GeneDx further reviewed the bioinformatics data obtained from the WES and verbally reported that the $14 \mathrm{q}$ deletion in the children was of paternal origin. The Mayo cytogenetics laboratory also reviewed and repeated the FISH studies for the father on metaphase cells. Ten out of 10 cells were negative for the deletion and no rearrangement was found.

\section{Discussion}

Chromosome 14q11-q22 deletion syndrome (OMIM 613457) is a rare genomic disorder with a variable phenotype. Over the years, several cases with de novo deletions have been reported. The common features of these patients include dysmorphic facial features, microcephaly, spastic tetraparetic cerebral palsy, developmental delay, intellectual disability, failure to thrive, behavioral problems, and intractable epilepsy. ${ }^{1-3}$ In our cases, the children were dysmorphic and globally delayed with intractable epilepsy, but they do not have spasticity or microcephaly.

We initially did not know if the deletions were of maternal or paternal origin, as the initial parental FISH results were negative. But with follow-up reviews and interpretations, this is very suggestive for a deletion of paternal origin with germline mosaicism in the father. The deletion was too small for a rearrangement to be detected reliably by karyotype. In addition, given the interstitial nature of this deletion and the negative metaphase FISH studies, a balanced translocation in the father is very unlikely. The father had a vasectomy such that sperm cytogenetic testing was not readily available.

The siblings share some clinical features but there are also differences between them. Only the sister has HLH. She is also showing better language development. This could be a benefit of earlier diagnosis and treatment of her seizures. The 3 VUS found in the brother's epilepsy gene panel were all present in one or the other of the asymptomatic parents, making them unlikely to be pathologic. The children's shared 14q13 microdeletion seems likely to be causative, although there is only limited evidence for this in the literature, and we suspect that the father has germline mosaicism for the deletion.

The one available report of a symptomatic 3.5-year-old child with a similar de novo $2-\mathrm{MB}$ deletion in the $14 \mathrm{q} 13$ region had a phenotype with some features in common with our patients, including generalized hypotonia, severe developmental delay, epilepsy, and $\mathrm{HLH}^{4}{ }^{4}$ His dysmorphic features were unlike those of our patients, with frontal bossing, a small face, a pointed chin, a deep philtrum, and a small penis. In the photograph included in the case report, he appeared to have a short columella. His seizures were of focal onset and associated with apnea, without infantile spasms, but he was reportedly also resistant to multiple anticonvulsants, including phenobarbital, valproic acid, oxcarbazepine, and sultiam. He reportedly died 5 weeks into treatment for his $\mathrm{HLH}$ with the same 2004 protocol used in our patient. The genetic changes among the 3 children had a nearly complete overlap (table).

We have continued to learn about this syndrome through the identification of new genes in the deleted region. As mentioned by Caliebe et al., ${ }^{4}$ the etiology of HLH was unknown. NFKBIA haploinsufficiency may be related to immunodeficiency. ${ }^{5,6}$ However, whether NFKBIA haploinsufficiency was a predisposing factor for $\mathrm{HLH}$ is controversial. Both of our patients had NFKBIA haploinsufficiency and yet only one developed HLH.

Testing in the brother revealed 3 VUS in epilepsy-associated genes that were all inherited from his nonaffected parents. The sister had normal results with an epilepsy gene panel 
Table Comparison of phenotypes and genotypes within the family and in the literature

\begin{tabular}{|c|c|c|c|c|c|}
\hline & Brother & Sister & Father & Mother & Caliebe et al. ${ }^{4}$ \\
\hline \multicolumn{6}{|l|}{ Phenotype } \\
\hline Intractable epilepsy with IS & Yes & Yes & No & No & Yes, but no IS \\
\hline GDD/ID with hypotonia & Yes & Yes & No & No & Yes \\
\hline Dysmorphic features & Yes & Yes & No & No & Yes \\
\hline Cortical visual impairment & Yes & Yes & No & No & NA \\
\hline Hearing loss & Yes & No & No & No & NA \\
\hline HLH & No & Yes & No & No & Yes \\
\hline \multicolumn{6}{|l|}{ Imaging studies } \\
\hline $\begin{array}{l}\text { Brain MRI w bilateral } \\
\text { choroid plexus cysts }\end{array}$ & Yes & Yes & Not done & Not done & NA \\
\hline Brain MRS & Not done & Normal & Not done & Not done & NA \\
\hline \multicolumn{6}{|l|}{ Genetic studies } \\
\hline $14 q 13$ microdeletion & Yes & Yes & Absent & Absent & Yes \\
\hline Testing method & Array CGH & SNP microarray & FISH & FISH & Array CGH \\
\hline Year of report & 2010, with an update in 2017 & 2016 & & & 2011 \\
\hline Deleted region & $(33,301,123-35,730,707)[\mathrm{hg} 18]$ & $(34,211,404-36,648,257)[\mathrm{hg} 19]$ & & & $(33,705,717 \times 2,33,740,150-35,694,522 \times 1,35,817,248 \times 2)$ \\
\hline Deletion size & $2.4 \mathrm{MB}, 22$ known genes & $2.4 \mathrm{MB}, 21$ known genes & & & $2 \mathrm{MB}, 14$ known genes \\
\hline Genes involved & $\begin{array}{l}\text { NPAS3, EGLN3, SPTSSA, EAPP, SNX6, CFL2, BAZ1A, } \\
\text { IGBP1P1, SRP54, FAM177A1, PPP2R3C, } \\
\text { LOC101927178, KIAA0391, PSMA6, NFKBIA, INSM2, } \\
\text { RALGAPA1, RALGAPA1P1, SNORA101B, BRMS1L, } \\
\text { LINC00609, PTCSC3 }\end{array}$ & $\begin{array}{l}\text { NPAS3, EGLN3, SPTSSA, EAPP, SNX6, CFL2, BAZ1A, } \\
\text { IGBP1P1, SRP54, FAM177A1, PPP2R3C, } \\
\text { LOC101927178, KIAA0391, PSMA6, NFKBIA, INSM2, } \\
\text { RALGAPA1, RALGAPA1P1, BRMS1L, LINCO0609, } \\
\text { PTCSC3 }\end{array}$ & & & $\begin{array}{l}\text { C14orf147, C14orf11, SNX6, CFL2, BAZ1A, SRP54, } \\
\text { C14orf24, C14orf10, KIAA0391, PSMA6, NFKBIA, INSM2, } \\
\text { GARNL1, and BRMS1L }\end{array}$ \\
\hline VUS in SZT2 and ASPM & Yes & Not done & No & Yes & NA \\
\hline VUS in PTCH1 & Yes & Not done & Yes & No & NA \\
\hline Normal WES & Yes & Yes & Yes & Yes & NA \\
\hline
\end{tabular}

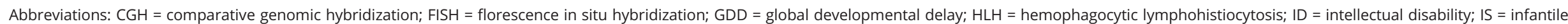
spasms; MRS = magnetic resonance spectroscopy; NA = not applicable; SNP = single nucleotide polymorphisms; VUS = variant of uncertain significance; WES = whole exome sequencing. 
from a different laboratory that did not include the 3 genes in which VUS were found in the brother. WES revealed no pathogenic variants in the sister and she did not inherit the VUS seen in the brother and their parents. We conclude that the common $14 \mathrm{q} 13$ microdeletion was the cause of the neurodevelopmental and clinical phenotype seen in these siblings (table). These cases narrowed the critical region for intractable epilepsy to $14 \mathrm{q} 13.1-14 \mathrm{q} 13.3$ within the $14 \mathrm{q} 11-\mathrm{q} 22$ deletion syndrome.

In terms of genetic testing for familial epilepsy, we recommend starting from a broad approach, such as a karyotype, to evaluate for balanced translocations, inversions, and mosaicism, and an SNP chromosomal microarray, to evaluate for copy number changes. Additional genetic testing should focus on sequence alterations in specific genes associated with epilepsy. Next generation sequencing has made it possible to test large numbers of genes simultaneously at a reasonable cost. Several such panels are commercially available but they include different genes, making panel selection difficult. It is important to choose a panel that includes the genes that are most consistent with patient's phenotype. For example, in these patients, a gene panel with good coverage of early infantile epileptic encephalopathy is preferable to one more suited to later onset and less malignant forms of epilepsy. Use of a more specific panel reduces the number of potential VUS that need to be further analyzed.

From a cost-efficiency standpoint, if more than 2 panels are necessary to include all the suspected genetic changes, a WES test is preferable. When a VUS is detected in a condition with an autosomal recessive inheritance pattern, it can be helpful to review the patient's phenotype and determine whether targeted gene testing would be helpful to evaluate for deletion or duplication of the other allele. It is also helpful to revisit the genetic study results with the original testing laboratory on a regular basis as our ability to interpret VUS grows.

Sometimes a circuitous pathway toward a genetic diagnosis is unavoidable given the complexity and variable expression of neurologic diseases. Specialists in Neurology and genetics benefit from maintaining long-term relationships with their patients, allowing reevaluation of phenotypes and available test options. Our cases illustrate the value of a multidisciplinary and long-term approach to diagnosis with input from genetics and child neurology in the evaluation of familial epilepsy. The challenges faced in coordinating and interpreting genetic tests, especially when more than one laboratory is involved, and as tests and interpretations evolve over time can be overcome.

\section{Author contributions}

Drs. Liu and Gold: study concept and design. Dr. Liu: acquisition of data. Drs. Liu, Michelson, Clark, and Gold: analysis and interpretation. Drs. Michelson, Clark, and Gold: critical revision of the manuscript for important intellectual content. Dr. Gold: study supervision.

\section{Acknowledgment}

The authors thank the family for allowing them to care for their children and for allowing us to share their story.

\section{Study funding}

No targeted funding reported.

\section{Disclosure}

The authors report no disclosures relevant to the manuscript. Go to Neurology.org/N for full disclosures.

\section{References}

1. Torgyekes E, Shanske AL, Anyane-Yeboa K, et al. The proximal chromosome $14 \mathrm{q}$ microdeletion syndrome: delineation of the phenotype using high resolution SNP oligonucleotide microarray analysis (SOMA) and review of the literature. Am J Med Genet A 2011;155A:1884-1896.

2. Ramelli GP, Remonda L, Lovblad KO, Hirsiger H, Moser H. Abnormal myelination in a patient with deletion 14q11.2q13.1. Pediatr Neurol 2000;23:170-172.

3. Shimojima K, Komoike Y, Tohyama J, et al. TULIP1 (RALGAPA1) haploinsufficiency with brain development delay. Genomics 2009;94:414-422.

4. Caliebe A, Martin Subero JI, Muhle H, et al. A 2 Mb deletion in $14 \mathrm{q} 13$ associated with severe developmental delay and hemophagocytic lymphohistiocytosis. Eur J Med Genet 2011;54:e505-509.

5. Lopez-Granados E, Keenan JE, Kinney MC, et al. A novel mutation in NFKBIA/IKBA results in a degradation-resistant $\mathrm{N}$-truncated protein and is associated with ectodermal dysplasia with immunodeficiency. Hum Mutat 2008;29:861-868.

6. Yoshioka T, Nishikomori R, Hara J, et al. Autosomal dominant anhidrotic ectodermal dysplasia with immunodeficiency caused by a novel NFKBIA mutation, p.Ser36Tyr, presents with mild ectodermal dysplasia and non-infectious systemic inflammation. J Clin Immunol 2013;33:1165-1174.

\section{Subspecialty Alerts by E-mail!}

Customize your online journal experience by signing up for e-mail alerts related to your subspecialty or area of interest. Access this free service by clicking on the "My Alerts" link on the home page. An extensive list of subspecialties, methods, and study design choices will be available for you to choose from-allowing you priority alerts to cutting-edge research in your field! 


\section{Neurology}

\section{Child Neurology: Siblings with infantile epilepsy and developmental delay: A circuitous path to genomic diagnosis}

Yin Liu, David Michelson, Robin Clark, et al.

Neurology 2018;91;143-147

DOI 10.1212/WNL.0000000000005815

This information is current as of July 16, 2018

\section{Updated Information \&} Services

\section{References}

Subspecialty Collections

\section{Permissions \& Licensing}

Reprints including high resolution figures, can be found at: http://n.neurology.org/content/91/3/143.full

This article cites 6 articles, 0 of which you can access for free at: http://n.neurology.org/content/91/3/143.full\#ref-list-1

This article, along with others on similar topics, appears in the following collection(s):

\section{All Genetics}

http://n.neurology.org/cgi/collection/all_genetics

Developmental disorders

http://n.neurology.org/cgi/collection/developmental_disorders

Generalized seizures

http://n.neurology.org/cgi/collection/generalized_seizures

Infantile spasms

http://n.neurology.org/cgi/collection/infantile_spasms

Neonatal seizures

http://n.neurology.org/cgi/collection/neonatal_seizures

Information about reproducing this article in parts (figures,tables) or in its entirety can be found online at:

http://www.neurology.org/about/about_the_journal\#permissions

Information about ordering reprints can be found online:

http://n.neurology.org/subscribers/advertise

Neurology ${ }^{\circledR}$ is the official journal of the American Academy of Neurology. Published continuously since 1951, it is now a weekly with 48 issues per year. Copyright (O 2018 American Academy of Neurology. All rights reserved. Print ISSN: 0028-3878. Online ISSN: 1526-632X.

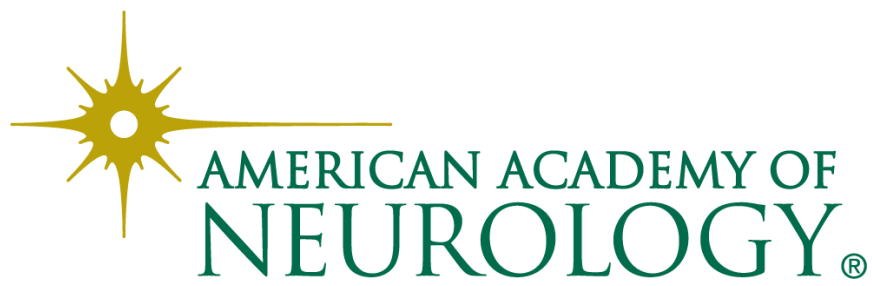

